\title{
Perfil físico-químico e sensorial de sucos de uva brancos produzidos por extração a quente
}

\begin{tabular}{lr}
\hline Angelica Bender & Universidade Federal de Pelotas, UFPel- Capão do Leão, RS - Brasil. \\
Marcelo Barbosa Malgarim & E-mails: bender.angelica.fruti@gmail.com \\
Suélen Braga de Andrade & $\begin{array}{r}\frac{\text { malgarim@ufpel.edu.br }}{\text { suelenb.andrade@gmail.com }} \\
\hline \text { André Luiz Kulkamp de Souza }\end{array}$ \\
$\begin{array}{l}\text { Empresa de Pesquisa e Extensão Rural de Santa Catarina, Epagri - } \\
\text { Estação Experimental de Videira, Videira SC. }\end{array}$ \\
E-mails: andresouza@epagri.sc.gov.br \\
caliari@epagri.sc.gov.br
\end{tabular}

Recebido em: 21 nov. 2018. Aceito em: 18 dez. 2018.

DOI: http://dx.doi.org/10.21674/2448-0479.45.743-751

\section{Resumo}

Existem diferentes tecnologias de elaboração de suco de uva, sendo a mais comum por aquecimento, que pode ser realizado por trocadores de calor para grandes volumes, ou por vapor para volumes menores. O objetivo desse trabalho foi avaliar a influência do uso de diferentes técnicas de extração empregando calor na composição físico-química e aceitação sensorial de sucos de uvas brancas. O trabalho foi realizado na Epagri - Estação experimental de Videira, com uvas da variedade Niágara Branca (Vitis labrusca), safra 2018. Os tratamentos consistiram em: 1) Extração em panela extratora por arraste de vapor; 2) Extração por sistema adaptado simulando trocador de calor e adição de enzimas pectolíticas. Os sucos foram avaliados quanto à composição físico-química e sensorial. Os sucos elaborados por trocador de calor apresentaram valores mais elevados para acidez titulável, sólidos solúveis, açúcares redutores totais, bem como maior intensidade de cor. Os sucos extraídos por arraste de vapor destacaram-se pela maior relação açúcar/acidez. Sensorialmente não ocorreram diferenças significativas, porém, os sucos elaborados por trocador de calor receberam maiores notas para os parâmetros avaliados, exceto equilíbrio açúcar/acidez e doçura. Sucos elaborados com uso de enzimas e trocador de calor apresentaram maior doçura e acidez, recebendo maiores notas para cor, aroma agradável, acidez, corpo, adstringência e impressão global. Sucos obtidos pela extração a vapor apresentaram menor acidez culminando em uma maior relação açúcar/acidez.

Palavras-chave: Niágara Branca. Vapor. Trocador de calor. Aquecimento.

\section{Abstract}

\section{Physicochemical and sensory profile of white grape juice produced by heat-based extraction}

There are different technologies for making grape juice, however, the most common is through heating, which can be carried out by heat exchangers for large volumes, or by steam for smaller volumes. The objective of the present study was to evaluate the influence of the use of the different heat-based extraction techniques on the physicochemical composition and sensorial acceptance of 
white grape juice. The study was carried out at Epagri - Videira Experimental Station, with the White Niagara (Vitis labrusca) grape variety, the 2018 harvest. The treatments consisted of: 1) Extraction in extractor pan by steam drag; 2) Extraction by an adapted system simulating heat exchanger and addition of pectolytic enzymes. Juices were evaluated for physicochemical and sensorial composition. Juices elaborated by heat exchanger presented higher values for titratable acidity, soluble solids, total reducing sugars, as well as higher color intensity, juices extractor pan by steam drag were distinguished by the higher sugar/acidity ratio. In sensorial terms, no significant differences were observed in the juice, but the juice elaborated by heat exchanger received higher scores for the evaluated parameters, except sugar/acid balance and sweetness. Juices elaborated using enzymes and heat exchanger presented greater sweetness and acidity, receiving higher scores for color, pleasant aroma, acidity, body, astringency and overall impression. Juices obtained by steam extraction showed lower acidity, culminating in a higher sugar/acidity ratio.

Keywords: White Niagara. Steam. Heat exchanger. Heating.

\section{Introdução}

Os potenciais benefícios para a saúde associados ao suco de uva têm atraído a atenção dos consumidores, devido a atual preocupação desses com uma alimentação saudável, acarretando um aumento de $570 \%$ na comercialização da bebida em todo o mundo nos últimos 10 anos (MOTA et al. 2018). No Brasil, a produção de suco no ano de 2005 foi de 28 milhões de litros atingindo quase 88 milhões em 2015, triplicando o volume em uma década, e as vendas quase quadruplicaram neste mesmo período, passando de 38 milhões para mais de 150 milhões de litros (FONGARO et al., 2016; MELLO; MACHADO, 2018).

Sabe-se que a qualidade do suco está intimamente associada às condições de elaboração. De acordo com Rizzon e Meneguzzo (2007) e Fongaro et al. (2016), várias são as metodologias empregadas na elaboração de suco de uva, sendo mais comum o uso das seguintes etapas: desengace e esmagamento, aquecimento, adição de enzimas pectolíticas, extração do suco, clarificação, pasteurização e envase. No caso de sucos brancos, alguns produtores costumam remover as cascas antes do aquecimento. As uvas podem ser aquecidas com o emprego de trocadores de calor, também conhecidos como tubo em tubo, utilizado para médios e grandes volumes. Para elaboração em pequena escala, utiliza-se panelas extratoras por arraste de vapor (GUERRA et al., 2016).

Após o processamento o suco integral deve manter as características sensoriais marcantes da fruta que o gerou, uma vez que os consumidores apreciam os produtos de uva, cujos atributos sensoriais são percebidos em alta intensidade e apresentam equilíbrio entre si (MARCON, 2013). As principais variedades de uva empregadas na elaboração de sucos são do grupo das americanas, pois além de preservarem os aspectos de fruta fresca após o aquecimento, apresentam potencial antioxidante (TOALDO et al., 2013). Dani et al. (2007) e Toaldo et al. (2015) avaliaram o potencial de compostos bioativos em sucos de uvas Vitis labrusca, concluindo que tanto os sucos brancos como os tintos são boas fontes de antioxidantes. 
A variedade Niágara Branca é uma das mais plantadas no Brasil, sendo destinada ao consumo in natura, no entanto, suas características favoráveis para o processamento à torna uma alternativa de matéria-prima para elaboração de sucos, devido as suas características de aroma e sabor, com aceitação elevada entre os consumidores (SILVA et al., 2017).

O constante crescimento da produção de sucos de uva no Brasil demanda estudos que associem à qualidade da uva e as tecnologias de processamento para garantir a qualidade do produto final. Mediante a este contexto, o objetivo desse trabalho foi avaliar a influência do uso de diferentes técnicas de extração, empregando calor na composição físico-química e aceitação sensorial de sucos de uvas brancas.

\section{Materiais e Métodos}

O trabalho foi realizado na Epagri - Empresa de Pesquisa Agropecuária e Extensão Rural de Santa Catarina, Estação Experimental de Videira (Videira, SC/Brasil), localizada sob a coordenada latitude $27^{\circ} 02^{\prime} 27,59^{\prime \prime} \mathrm{S}$, longitude $51^{\circ} 08^{\prime} 04,73^{\prime \prime} \mathrm{W}$, altitude de 830 metros acima do nível do mar, durante o ciclo produtivo 2017/2018. O clima da região de acordo com Köppen é classificado como mesotérmico úmido e verão ameno (Cfb). As médias históricas (1960-2016) de precipitação, temperatura média e umidade relativa nos meses que englobam a brotação e colheita (setembro a março) são de $1.240 \mathrm{~mm}, 19,8^{\circ} \mathrm{C}$ e $73,4 \%$ UR, respectivamente (EPAGRI/CIRAM).

O vinhedo foi implantado em 2008 no campo Experimental da Epagri-Videira no sistema de condução em ípsilon ( $Y$ ) ou manjedoura sob o porta-enxerto VR 043-43 em espaçamento de 3,0 $\mathrm{x}$ 2,0m, entre linhas e entre plantas, respectivamente, totalizando 1666,66 plantas/ha.

Foi realizado o acompanhamento da maturação, por meio de coletas semanais de amostras representativas do vinhedo, a data da colheita foi definida no momento em que o teor de sólidos solúveis se manteve constante e a relação SS/AT apresentou-se acima de 20 considerada ideal por Chouhury et al. (2001). A colheita foi realizada em 11 de janeiro de 2018, de maneira manual e as uvas acondicionadas em caixas plásticas com capacidade de até $20 \mathrm{~kg}$. As bagas foram avaliadas no momento da colheita apresentando um $\mathrm{pH}$ de 3,6, teor de sólidos solúveis de 14,6 ${ }^{\circ}$ Brix e 49,4 $\mathrm{mEq} . \mathrm{L}^{-1}$ em acidez titulável, com uma relação SS/AT de 39,5. Depois de concluída a colheita, foram elaborados os sucos na cantina experimental da Epagri-Videira-SC, empregando as tecnologias de extração: 1) Extração em panela extratora por arraste de vapor; 2) Extração por sistema adaptado simulando trocador de calor e adição de enzimas pectolíticas.

No tratamento 1, a extração do mosto ocorreu com extrator de suco ou panela extratora com capacidade para $20 \mathrm{~kg}$ de fruta. Inicialmente as bagas foram desengaçadas com auxílio de desengaçadeira manual e posteriormente, colocadas no recipiente perfurado, encaixado no recipiente externo, e ambos acoplados sobre o depósito de água, que foi acomodado sobre fogareiro a gás, para geração de vapor. Após aproximadamente 20 minutos, o mosto começou a fluir através do tubo de saída sendo recolhido em recipiente denominada de panela pulmão para homogeneização do suco, mantido sobre fogo para manter o suco aquecido. $O$ engarrafamento das amostras ocorreu assim que a massa sólida se mostrou exaurida de líquido, o envase ocorreu a uma temperatura de $86^{\circ} \mathrm{C}$.

O tratamento 2 consistiu em desengace mecânico, onde após esse processo, as bagas foram colocadas em recipiente de alumínio sobre fogareiro a gás, para o aquecimento até $50^{\circ} \mathrm{C}$. Adicionou-se complexo enzimático termo resistente comercial (Pectinex Ultra SP-L) na concentração 
de $3 \mathrm{~g} \mathrm{hL}^{-1}$. Após aproximadamente 20 minutos de constante homogeneização, o mosto juntamente com o bagaço atingiu a temperatura desejada, sendo retirado do fogo e mantido por uma hora em maceração. Posteriormente, realizou-se a prensagem para separação do líquido, que foi conduzido para a câmara fria a uma temperatura de $\pm 1^{\circ} \mathrm{C}$, para decantação das partículas sólidas por um período de 24 horas. No dia seguinte, o suco foi trasfegado, pasteurizado e engarrafado a uma temperatura de $86^{\circ} \mathrm{C}$.

Os sucos foram envasados em garrafas de vidro transparente com capacidade de $500 \mathrm{~mL}$, mantidas em temperatura ambiente em local próprio para armazenamento de bebidas livre de odores e com baixa luminosidade até o momento da execução das análises físico-químicas e sensoriais.

O experimento contou com delineamento inteiramente casualizado, com 5 repetições contendo 3 plantas cada no vinhedo, que foram avaliadas individualmente e posteriormente homogeneizadas para a elaboração dos sucos, que consistiram de 3 repetições, onde cada repetição foi representada por uma garrafa, escolhidas aleatoriamente para as análises físico-químicas (realizadas em triplicata), em esquema monofatorial. A análise sensorial contou com 10 avaliadores com experiência em análise sensorial, onde cada avaliador representou uma repetição.

As análises físico-químicas de acidez total (AT), teor de sólidos solúveis (SS), relação SS/AT e $\mathrm{pH}$, foram realizadas nas uvas antes do processamento, bem como, no suco finalizado, seguindo Instrução Normativa n 24 de 08 de setembro de 2005 (BRASIL, 2005). O teor de sólidos solúveis foi determinado em refratômetro digital de bancada com compensação automática de temperatura $\left(\right.$ QUIMIS $^{\circledR}$ ), e o resultado expresso em ${ }^{\circ}$ Brix. O pH foi determinado em pHmetro Meter AD1030 e as determinações de acidez total foram realizadas por titulação da mostra, com solução padronizada de $\mathrm{NaOH} 0,1 \mathrm{~N}$, adotando-se, como ponto final da titulação $\circ \mathrm{pH}=8,2$, e o resultado expresso em mEq.L 1. A relação SS/AT foi determinada pela obtenção do quociente da divisão entre os sólidos solúveis ( ${ }^{\circ}$ Brix) e acidez titulável em g $100 \mathrm{~mL}^{-1}$ de ácido tartárico.

Os sucos foram avaliados ainda quanto os açúcares redutores totais $\left(\mathrm{g} . \mathrm{L}^{-1}\right)$ utilizando o método DNS descrito por Maldonade et al. (2013), adaptado para suco de uva. Densidade foi determinada com um densímetro de vidro Aton Paar, expressa em $\mathrm{g} . \mathrm{cm}^{3}$. Para avaliar a coloração dos sucos foi empregado o uso do espectrofotômetro da Konica Minolta, modelo CM-5, pesquisando as coordenadas $L^{*}, a^{*} e b^{*}$. Sendo que o $L^{*}$ representa a luminosidade da amostra e os valores de $a^{*}$ e $b^{*}$ foram empregados no cálculos da saturação (croma) e tonalidade ( $\left.{ }^{\circ} \mathrm{HUE}\right)$ da cor, obtidas pelas seguintes fórmulas $C^{*}=\left[\left(a^{*}\right)^{2}+\left(b^{*}\right)^{2}\right]^{1 / 4}$ e $H^{\circ}=\arctan b^{*} / a^{*}$, respectivamente, conforme recomendações de McGuire (1992).

A análise sensorial foi realizada na Epagri Videira-SC, com aprovação do Comitê de Ética em Pesquisa com seres humanos da Universidade Federal de Pelotas, sob protocolo CAAE 92226218.8.0000.5317, por um grupo de 10 pessoas previamente treinadas. Foram avaliados os atributos: intensidade de cor, aroma agradável, aroma desagradável, acidez, doçura, equilíbrio doçura/acidez, corpo, adstringência e aceitação global das amostras de suco de uva, usando uma escala hedônica de nove pontos. Os avaliadores receberam as amostras $\left(20 \pm 1^{\circ} \mathrm{C}\right)$ de forma aleatória em taças de vidro codificadas com três dígitos aleatórios, juntamente com a escala.

Os dados foram submetidos à análise de variância (ANOVA) e quando detectadas efeitos de tratamento, procedeu-se o teste de comparação de médias pelo Teste Tukey a $5 \%$ de probabilidade de erro.

\section{Resultados e Discussão}


Os resultados encontrados para as análises físico-químicas dos sucos de 'Niágara Branca' estão listados na Tabela 1. As variáveis analisadas apresentaram diferenças significativas pelo teste de Tukey $(<0,05)$, exceto para a tonalidade de cor.

$\mathrm{O}$ valor de $\mathrm{pH}$ na extração a vapor foi superior ao verificado nos sucos obtidos por extração via trocador de calor, 3,22 e 3,17, respectivamente. Resultados inferiores aos verificados por Lima et al. (2015) para sucos das variedades Isabel Precoce e BRS Cora produzidos em escala industrial, empregando diferentes processos de maceração, onde os valores referenciados oscilaram entre 3,5 e 3,9. Fongaro et al. (2016) estudaram a evolução físico-química de sucos brancos e tintos produzidos na Serra Gaúcha dentre os anos de 2012 a 2016, verificando o menor valor de pH para os sucos brancos de 3,19 no ano de 2013 e o maior em 2014 com 3,32, valores próximos aos verificados no presente estudo.

Os teores de sólidos solúveis totais $\left(14,0^{\circ}\right.$ Brix) e acidez titulável $\left(55 \mathrm{mEq} \cdot \mathrm{L}^{-1}\right)$ para sucos de uva integrais são determinados em lei (BRASIL, 2018). Os sucos obtidos pelo método de extração a vapor não atingiram o valor estipulado para sólidos solúveis totais $\left(12,4^{\circ} \mathrm{Brix}\right)$. Para acidez titulável ambos os sucos ficaram condizentes com a legislação. Ao comparar os resultados obtidos nos sucos com aqueles observados nas respectivas uvas empregadas na elaboração, verificou-se menor teor de sólidos solúveis totais especialmente nos sucos produzidos por arraste de vapor, e uma maior acidez titulável em ambos os tratamentos. Marcon et al. (2016) alegam que durante a elaboração de sucos por extração a vapor pode ocorrer uma incorporação de água exógena nos sucos, oriunda da condensação do vapor gerado para aquecimento das bagas, esses valores podem variar de $7,56 \%$ a $20,7 \%$, fator que pode prejudicar o teor de sólidos solúveis totais no suco. Esses mesmos autores afirmam que no método de extração por trocador de calor não ocorre à incorporação de água nos sucos. Lima et al. (2015) e Mota et al. (2018) corroboram com os resultados observados, alegando que o uso de altas temperaturas no momento da extração pode causar plasmólise da membrana celular resultando na ruptura da parede celular da fruta, facilitando a liberação da água, no entanto, também facilita a extração de ácidos da casca e sementes que contribuem para uma maior acidez. $\mathrm{O}$ uso de enzimas pectolíticas empregadas na extração dos sucos no tratamento 2 também apresenta influência na extração de compostos da baga, acarretando em teores mais elevados para sólidos solúveis e acidez.

Quanto à relação SS/AT os sucos analisados apresentaram valores de 17,5 para os sucos extraídos por vapor e 16,4 para os sucos obtidos com trocador de calor, mostrando-se inferiores ao verificados nas uvas antes do processamento, consequência da elevação da acidez e redução dos sólidos solúveis após o processamento. Estes valores mostraram-se inferiores aos encontrados por Lima et al. (2014) em sucos produzidos com uvas americanas e híbridas no estado de Pernambuco/BR, onde o menor valor verificado pelos autores foi de 19,8. Lima et al. (2015) também verificaram resultados superior para sucos de 'Isabel Precoce' e 'BRS Cora' em diferentes condições de maceração.

Tabela 1: Médias dos parâmetros físico-químicos de sucos brancos produzidos por extração a quente.

\begin{tabular}{crrr}
\hline \multirow{2}{*}{ Variáveis Físico-Químicas } & \multicolumn{3}{c}{ Métodos de extração } \\
\cline { 2 - 4 } & T1 & T2 & \\
\hline pH & 3,22 & $\mathrm{a}^{*}$ & $3,17^{\mathrm{b}}$ \\
Sólidos Solúveis totais ( ${ }^{\circ}$ Brix) & 12,40 & $\mathrm{~b}^{\mathrm{b}}$ & $14,40^{\mathrm{a}}$
\end{tabular}

Rev. Elet. Cient. UERGS, v.4, n5, p. 743-751, 2018. 


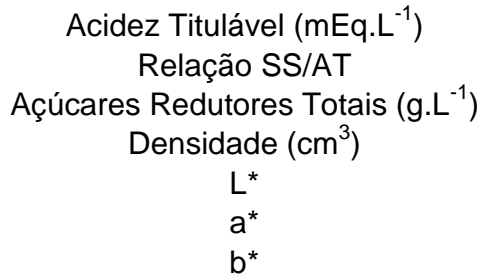

Tonalidade de cor ( $\left.{ }^{\circ} \mathrm{HUE}\right)$

Intensidade de cor (Chroma)

$\begin{array}{rlrl}94,30 & \mathrm{~b} & 116,90 & \mathrm{a} \\ 17,50 & \mathrm{a} & 16,40 & \mathrm{~b} \\ 131,90 & \mathrm{~b} & 162,60 & \mathrm{a} \\ 1,05 & \mathrm{~b} & 1,06 & \mathrm{a} \\ 92,90 & \mathrm{a} & 91,40 & \mathrm{~b} \\ 0,39 & \mathrm{~b} & 0,63 & \mathrm{a} \\ 9,40 & \mathrm{~b} & 13,70 & \mathrm{a} \\ 87,60 & \mathrm{a} & 87,40 & \mathrm{a} \\ 9,50 & \mathrm{~b} & 13,70 & \mathrm{a}\end{array}$

Valores seguidos pela mesma letra minúscula na linha não diferiram estatisticamente pelo teste de Tukey a $5 \%$ de probabilidade de erro para fator de tratamento tecnologias de extração de suco. T1- Extração por arraste de vapor; T2Extração por sistema adaptado simulando trocador de calor.

Para o teor de açúcares redutores totais os sucos oriundos do tratamento 2 apresentaram valor superior em relação aos extraídos por vapor. Quando comparada com outras frutas, a uva é rica em açúcares, principalmente glicose e frutose, sendo, por isso, considerado um alimento de alto valor energético (PENHEIRO et al., 2009; COSME et al, 2018). Os valores verificados nos sucos em questão foram superiores aos verificados por Santana et al. (2008) em sucos de variedades americanas comercializados no estado de Minas Gerais, onde os valores oscilaram de $114,9 \mathrm{~g} \cdot \mathrm{L}^{-1}$ a $127,4 \mathrm{~g} \cdot \mathrm{L}^{-1}$. Fongaro et al. (2016) encontraram uma média de $142 \mathrm{~g} \cdot \mathrm{L}^{-1}$ para sucos de uvas brancas do Estado do Rio Grande do Sul, nos anos de 2012 a 2016, valor intermediário aos encontrados nos sucos analisados. A densidade de mostos e sucos está intimamente relacionada ao teor de açúcares, o que explica a maior densidade apresentada pelos sucos oriundos do tratamento 2.

Para as variáveis relacionadas à cor dos sucos, não foram verificadas diferenças estatísticas para a tonalidade de cor, onde os valores obtidos indicam que os sucos apresentam uma coloração próxima ao amarelo de acordo com o diagrama CIELAB (CHITARRA; CHITARRA, 2005). De acordo com Gurak et al. (2012), as respostas de cor a e b indicam as direções das cores: +a para o vermelho, -a para o verde, $+b$ em direção ao amarelo e $-b$, ao azul. Com o aumento dos valores de a e b, o ponto se distancia do centro e a saturação da cor aumenta, corroborando com os resultados observados, pois os valores mais elevados obtidos para a e b dos sucos oriundos do tratamento 2 resultaram em uma maior tonalidade. Isso demonstra que esses possuem cor amarela mais intensa, provavelmente devido ao emprego de enzimas na extração, o que favoreceu uma maior extração de compostos das películas.

Não foram verificadas diferenças estatísticas dentro das variáveis sensoriais analisadas (Figura 1), porém é possível observar que os sucos elaborados pelo sistema enzimático receberam maiores notas para os parâmetros avaliados, exceto para o equilíbrio açúcar/acidez e doçura.

As maiores médias da relação equilíbrio açúcar/acidez e doçura dos sucos de extração a vapor podem ser justificadas pelo fato de que apesar desses sucos terem apresentado menor teor de sólidos solúveis, apresentando também uma menor acidez, culminando em um bom equilíbrio gustativo. Já os sucos da extração enzimática obtiveram mais açúcares, porém, a elevada acidez pode ter afetado a percepção da doçura pelos avaliadores.

A extração com o emprego de enzimas favorece a passagem dos compostos presentes nas bagas para o suco, dentre eles, ácidos, açúcares e compostos fenólicos, o que pode estar relacionada com as maiores médias de intensidade de cor, acidez, corpo e adstringência obtida nesses sucos. $O$ corpo está associado com a adstringência e ambas apresentam importante relação com a estrutura do suco. Esta estrutura se deve a quantidade de componentes da uva em especial taninos que são transferidos ao suco (RIZZON et al., 1998; BENDER et al., 2017). 


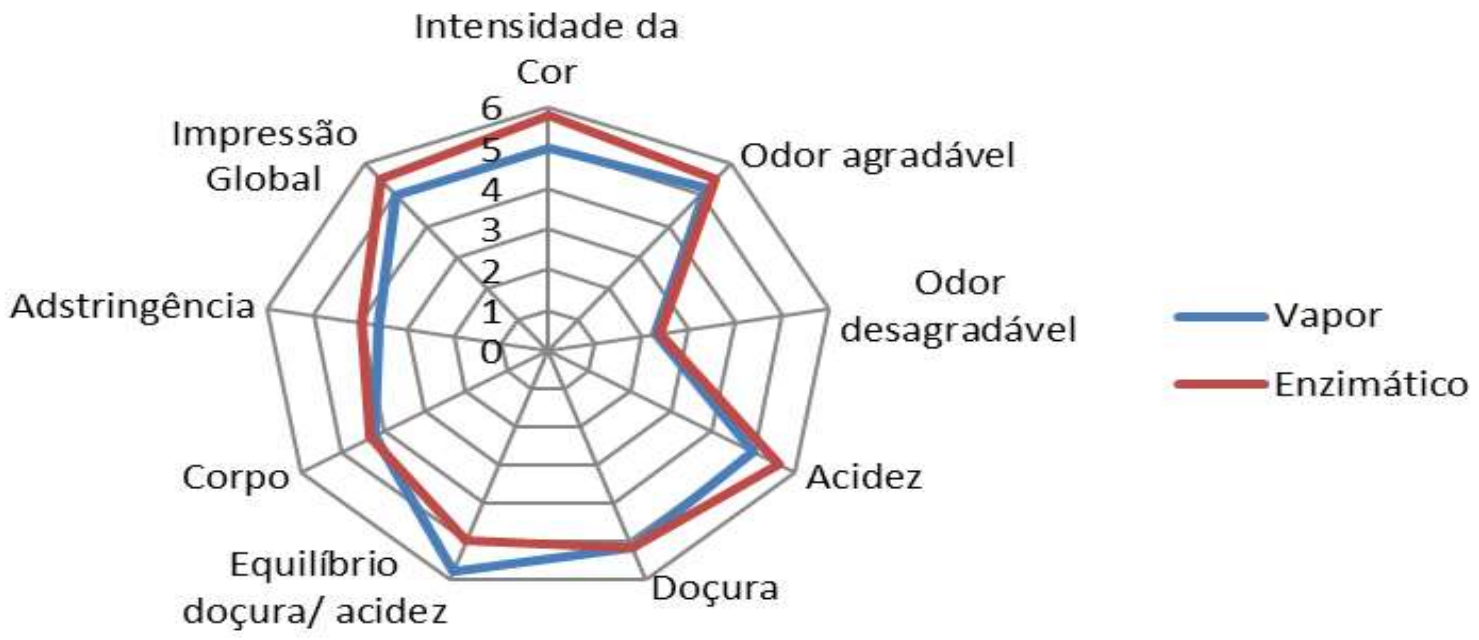

Figura 1: Aspectos sensoriais de sucos de uva brancos da variedade Niágara Branca produzidos por extração a quente.

Assim, como as sensações gustativas são determinantes da aceitação dos sucos, as variáveis olfativas são igualmente importantes, uma vez que estas são o segundo fator a ser avaliado durante a análise sensorial (MENEZZES et al., 2011). A nota dos sucos do tratamento enzimático foi de 5,5 para aroma agradável, indicando que o suco manteve as características de fruta fresca após o processamento. Bender et al. (2016) avaliaram sensorialmente sucos de diferentes variedades e espécies de uva, sendo que sucos das variedades Isabel e Niágara Branca apresentaram melhores notas para a variável de aroma, os autores relataram que estas uvas mantém o frescor após o processamento.

Os sucos elaborados por extração enzimática receberam notas maiores para impressão global, este resultado vai de encontro aos descritos por Canossa et al. (2017), que avaliaram sensorialmente os sucos das variedades Concord, Isabel Precoce e Bordo produzidos no município de Lages/SC, demonstrando que o suco da variedade Bordo apresentou maior intensidade de cor, bem como maiores notas de aroma, sabor e corpo, alegando que sucos com maior coloração, maior potencial aromático e maior presença de corpo e sabor são mais atrativos aos consumidores.

\section{Conclusão}

Sucos elaborados com uso de enzimas e trocador de calor apresentaram maiores teores de sólidos solúveis e acidez total. Não houve diferença estatística na avaliação sensorial dos sucos, porém aqueles elaborados por trocador de calor obtiveram notas maiores para cor, aroma agradável, acidez, corpo, adstringência e impressão global. Sucos obtidos pela extração a vapor apresentaram maior relação açúcar/acidez. 


\section{Referências}

BENDER, A.; COSTA, V.B.; RODRIGUES, C. M.; MALGARIM, M.B. Características sensoriais de sucos de uva elaborados com diferentes variedades e espécies. Revista da Jornada de Pós-Graduação e Pesquisa URCAMP, v.13, p.233-245, 2016.

BENDER, A.; MALGARIM, M.B.; COSTA, V.B.; SILVA, R. S. e; GUADAGNIN, V.; ANDRADE, S.B de. Influência de variedades de uvas Vitis vinifera nas características físico-químicas e na aceitação sensorial do suco. Ciência e Técnica Vitivinícola, v.32, n. 6, 2017.

BRASIL, Ministério da Saúde. Secretaria de Vigilância Sanitária. Instrução Normativa № 14, de 08 de fevereiro de 2018. Complementação dos padrões de identidade e qualidade do vinho e dos derivados da uva e do vinho. Diário Oficial da União. Brasília, 09 de março de 2018, Seção 1, p. 4-6.

BRASIL. Ministério da Agricultura, Pecuária e Abastecimento. Instrução normativa $n^{\circ} 24$, de 8 de setembro de 2005. Aprova o Manual Operacional de Bebidas e Vinagre. Diário Oficial [da] República Federativa do Brasil, Brasília, DF, 20 set. 2005.

CANOSSA, A.T.; REINEHR, J. ; BEM, B.P. de; ALLENBANDT, R.; WURZ, D.A; KRETZCHMAR, A.A. Composição química e análise sensorial do suco de uva elaborado com três variedades cultivadas em Lages - Santa Catarina. Revista da Jornada de Pós-Graduação e Pesquisa URCAMP, v.14, p.233-245, 2017.

CHITARRA, M. I. F.; CHITARRA, A. B. Pós-colheita de frutos e hortaliças: fisiologia e manuseio. 2 ed. Lavras: ESAL/FAEPE, 2005

CHOUDHURY, M. M. (Ed.). Uva de mesa: pós- -colheita. Brasília: Embrapa Informação Tecnológica; PetrolinaPE: Embrapa Semiárido, 55 p., 2001.

COSME, F.; PINTO, T.; VILELA, A. Phenolic Compounds and Antioxidant Activity in Grape Juices: a chemical and sensory view. Beverages, n.4, v.22, p.14, 2018.

DANI, C.; OLIBONI, L.S.; VANDERLINDE, R.; BONATTO, D.; SALVADOR, M.; HENRIQUES, J.A.P. Phenolic content and antioxidant activities of white and purple juices manufactured with organically- or conventionallyproduced grapes. Food and Chemical Toxicology, n. 45, p. 2574-2580, 2007.

DOWNEY, M.O.; KRSTIC, M.K.; DOKOOZLIAN, N.K. Cultural practice and environment impacts on the flavonoid composition of grapes and wine-A review of recent research. Am. J. Enol. Vitic., 57, 257-268, 2006.

FONGARO, C.; CAVAGNOLLI, N.I.; SPADA, P. K. W.D.S. Evaluation of physicochemical parameters of grape juices produced in the Serra Gaúcha. BIO Web of Conferences, 7, 01008, 2016. Disponível em: https://www.bioconferences.org/articles/bioconf/pdf/2016/02/bioconf-oiv2016_01008.pdf. Acesso em: 17 dez. 2018.

GUERRA, C.C.; BITARELO, H.; BEN, R.L. Sistema para Elaboração de Suco de Uva Integral em Pequenos Volumes: Suquificador Integral. Documentos n96, Bento Gonçalves, p. 32, 2016.

GURAK, P.D.; SILVA, M.C. da; MATTA, V.M. da; ROCHA-LEÃO, M.H.; CABRA, L. M. C. Avaliação de Parâmetros Físico-Químicos de Sucos de Uva Integral, Néctares de Uva e Néctares de Uva Light. Revista de Ciências Exatas, Rio de Janeiro, v. 27/31, n. 1, p. 07-22, 2012.

LIMA, M. dos S.; DUTRA, M. da C.P.; TOALDO, I.M.; CORRÊA, L.C.; PEREIRA, G.E.; OLIVEIRA, D. de; BORDIGNON-LUIZ, M.T.; NINOW, J.L. Phenolic compounds, organic acids and antioxidant activity of grape juices produced in industrial scale by different processes of maceration. Food Chemistry, n.188, p. 384-392, 2015.

LIMA, M. dos S.; SILANI, I. de S. V.; TOALDO, I.M.; CORRÊA, L.C.; BIASOTO, A.C.T.; PEREIRA, G.E.; BORDIGNON-LUIZ, M.T.; NINOW, J.L.; Phenolic compounds, organic acids and antioxidant activity of grape juices produced from new Brazilian varieties planted in the Northeast Region of Brazil. Food Chemistry, v. 161, p.94-103, 2014.

MALDONADE, I.R.; CARVALHO, P.G.B.; FERREIRA, N.A. Protocolo para determinação de açúcares totais em hortaliças pelo método DNS. Documentos n96, Embrapa, Brasília, p. 32, 2016. 
MARCON, A.R. Avaliação da incorporação de água exógena em suco de uva elaborado por diferentes processos, 2013. 63 f. Dissertação (Mestrado em Biotecnologia e Gestão Vitivinícola) - Universidade de Caxias do Sul, Caxias do Sul, 2013.

MARCON, Â.R.; DUTRA, S.V.; ROANI, C.A.; SPINELLI, F.R; LEONARDELLI, S.; VENTURIN, L.; VANDERLINDE, R. Avaliação da incorporação de água exógena em sucos de uva elaborados por panela extratora. Revista Brasileira de Viticultura e Enologia, n.8, p.52-57, 2016.

MCGUIRE, R. G. Reporting of objective color measurements. HortScience, v. 27, p. 1254-1555, 1992.

MELLO, L. M.R. de. Desempenho da vitivinicultura brasileira em 2017. Campo e negócio, Anuário 2018.

MELLO, L.M.R.; MACHADO, C.A.E. Dados da Viticultura. Brasília: Embrapa Informação Tecnológica, 2018. Disponível em: http://vitibrasil.cnpuv.embrapa.br/. Acesso em: setembro de 2018.

MENEZZES, F.; MESSIAS, G.M.; BARROS, N. E.F. Análise sensorial de suco de uva orgânico: teste de aceitação. Revista Eletrônica Novo Enfoque, v. 12, n. 12, p. 01, 2011.

MOTA, R.V. da; GLÓRIA, M.B.A.; SOUZA, B.S. de; PEREGRINO, I.; PIMENTEL, R. M. de A.; DIAS, F.A.N., SOUZA, L.C.de; SOUZA, A.L.de; REGINA, M. de A. Bioactive compounds and juice quality from selected grape cultivars. Bragantia, Campinas, v. 77, n. 1, p.62-73, 2018.

PINHEIRO, É. S.; COSTA, J.M.C.; CLEMENTE, E.; MACHADO, P.H.S.; MAIA, G.A. Estabilidade físico-química e mineral do suco de uva obtido por extração a vapor. Revista Ciência Agrotecnologia, Fortaleza, v. 40, n. 3, p. 373-380, 2009.

RIZZON, L. A.; MANFROI, V.; MENEGUZZO, J. Elaboração de suco de uva na propriedade vitivinícola, Bento Gonçalves: Embrapa Uva e Vinho, Circular Técnica n²1, 1998.

RIZZON, L. A.; MENEGUZZO, J. Suco de Uva. Brasília: Embrapa Informação Tecnológica, 2007.

SANTANA, M.T.A.; SIQUEIRA, H.H.; REIS, K.C.; LIMA, L.C.O.; SILVA, R.J.L; Caracterização de diferentes marcas de sucos de uva comercializados em duas regiões do Brasil. Ciência Agrotecnologia, Lavras, v. 32, n. 3, p. 882-886, 2008.

SILVA, T. K. R.; FARIA, C.M.D.R.; MAIA, A. J.; BOTELHO; R.V.; CALIXTO, R. Qualidade pós-colheita em uva 'Niágara Branca' submetida à aplicação de diferentes extratos vegetais. Revista Brasileira de Plantas Medicinais, São Paulo, v.19, n.1, p.1-7, 2017.

SREENATH, H.K.; SANTHANAM, K. The Use of Commercial Enzymes in White Grape Juice Clarification. Journal of fermentation and bioengineering, v. 73, n. 3, p. 241-243, 1992.

TOALDO, I.M.; CRUZ, F.A.; ALVES, T. de L.; GOIS, J.S. de; BORGES, D.L.G.; CUNHA, H.P.; SILVA, E.L. da; BORDIGNON-LUIZ, M.T. Bioactive potential of Vitis labrusca L. grape juices from the Southern Region of Brazil: Phenolic and elemental composition and effect on lipid peroxidation in healthy subjects. Food Chemistry, v. 173 p. 527-535, 2015.

TOALDO, I.M.; FOGOLARI, O.; PIMENTEL, G.C.; GOIS, J.S. de; BORGES, D.L.G.; CALIARI, V.; BORDIGNONLUIZ, M.T. Effect of grape seeds on the polyphenol bioactive content and elemental composition by ICP-MS of grape juices from Vitis labrusca L. LWT - Food Science and Technology, v. 53, p.1-8, 2013. 